\title{
Analysis of Reasons for Prospective Blood Donor Deferrals at Eric Williams Medical Sciences Complex Blood Collection Centre, in Trinidad and Tobago
}

Sehlule Vuma*, Hasina Mayers, George Legall and Angel Alberto Justiz Vaillant

Department of Paraclinical Sciences, The University of The West Indies, St Augustine, Trinidad and Tobago

*Corresponding author: Sehlule Vuma, Department of Paraclinical Sciences, The University of The West Indies, St Augustine, Trinidad and Tobago, Tel: +1-868-663-1141; E-mail: sehlule.vuma@sta.uwi.edu

Received date: Feb 17, 2015, Accepted date: Mar 26, 2015, Publication date: Mar 30, 2015

Copyright: @ 2015 Vuma S, et al. This is an open-access article distributed under the terms of the Creative Commons Attribution License, which permits unrestricted use, distribution, and reproduction in any medium, provided the original author and source are credited.

\begin{abstract}
Introduction: Blood banks must ensure reliability of blood supplies. However many prospective donors are temporarily deferred due to reasons that are preventable.
\end{abstract}

Objective: To describe the reasons for deferral of prospective blood donors at a local Blood Collection Centre.

Materials and Methods: This was a descriptive analysis of reasons for deferral of 488 prospective blood donors between April 2011 and May 2012. They were screened using the Pan American Health Organization 2009 guidelines. Haemoglobin was assessed using the Copper sulphate $\left(\mathrm{CuSO}_{4}\right)$

Method: 293 subjects (60.04\%), or HemoCue Hb201+: 195 subjects (39.96\%).

Results: $179(36.7 \%)$ were females aged 18 to 59years. The commonest reason for deferral was high blood pressure: 126donors (25.8\%). Others included lack of sleep 27 (5.5\%), not eating prior: 5(1.02\%), drank alcohol/ smoked prior, 9 (1.84\%), tattoo/piercing, 14 (2.87\%), breast feeding, inter-current illnesses, and "too soon" after a previous donation. 57(11.7\%), were deferred due to low haemoglobin. $16(28.1 \%)$, were screened using $\mathrm{CuSO}_{4}$ and 41(71.9\%) using HemoCue.

Conclusion: A high percentage of deferrals were due to hypertension or reasons that would not potentially endanger the blood recipients and could be prevented. This emphasizes the need for education of potential donor populations in order to avoid unfruitful blood bank visits. Deferrals based on low haemoglobin were higher using Hemocue method.

Keywords: Blood donors; Copper sulphate; Deferral; HemoCue, Safety

\section{Introduction}

Blood banks have to ensure reliability of blood supplies. Blood is a precious commodity available only because people are willing and are able to donate some of their own. Blood banks must be certain not only that that blood for transfusion is safe for the blood recipients but also that the donation process itself is safe for the donors. Stringent criteria are followed to achieve these. The accuracy of the information given by the donors during the screening process is very important. This information includes details of the donors' health and any social activities that they may engage in, that may expose them to or put them at risk of contracting infectious diseases, which are potentially transmittable to recipients. Supplying accurate health information also protects the donors themselves. Providing correct donation history is similarly important. From the screening process, prospective donors may be permanently or temporarily deferred. Those who are temporarily deferred may be less enthusiastic to return though [1]. Hence knowledge by prospective donors, of reasons for temporary deferral reduces the rate of these unfruitful visits to the blood bank. They need to be encouraged to return once the reason for the deferral has been corrected [2] as they are a valuable source of much needed blood. In Norway Misje et al. [3] showed that younger donors were deferred due to lifestyle reasons like drugs and body piercings. Older people were more likely to be deferred due to illnesses. Deferred repeat donors were more likely to return than deferred first time donors. In the United States of America [4], Custer et al. reported that temporary deferrals of shorter duration were more likely to return than those who were longer term deferrals. However most of the temporary deferrals were actually unlikely to be a threat to the transfusion recipient [4].

The voluntary donor, who is an unpaid and a regular donor, has the least risk of having transfusion-transmittable infections [1,5]. This is the best donor in order to meet blood demands. Hakon Reikvam, et al. [1], in their study in Norway, a European setting, where the donors are in fact regular voluntary donors, showed that a high number of deferrals were due to an inter-current illness. Other reasons included some that would actually not put the health of the recipient of blood in any danger at all as reported by Custer et al. [4]. In an Indian study by Jashnani et al. [5], where donors included both "long and short term donors", the second commonest reason for deferral was high blood pressure. These writers recommended that prospective donors who are known to be hypertensive could have their blood pressure checked a few days prior to presenting to the blood bank. The commonest reason for deferral among female donors was low haemoglobin. In a West African setting, in Ivory Coast [6] where donors were voluntary, and 
Page 2 of 5

where $77.4 \%$ of deferred prospective donors were repeat donors, (and $22.6 \%$ first time donors), the commonest reason for deferral, $(42.5 \%)$ was low haemoglobin (seen mostly among female donors) and change in sexual partners (34.3\%), (seen mostly among male donors). A small percentage $(4.5 \%)$ was due to presenting too soon after a previous donation. In another West African setting, in Nigeria, [7], where $89.1 \%$ were replacement donors, more female donors were deferred than males. $25.6 \%$ were female donors with low haemoglobin versus $12.7 \%$ in male donors. Hypertension accounted only for $3.1 \%$ of the total deferrals.

The population of Trinidad and Tobago is about 1.3 million, made up of about $34.2 \%$ people of West African origin, 35.4\% East Indian origin, $22.8 \%$ mixed heritage (made up of $7.6 \%$ African/East Indian mix, and $15.2 \%$ other ethnic groups mixed), and the rest include Caucasian, Chinese, Portuguese, Syrian/Lebanese, Indigenous people and those of other ethnic groups [8]. Of the total population approximately 834,000 are potential blood donors however blood shortages are common. In this setting, the majority of blood donors are not voluntary but replacement donors. In spite of all these blood shortages, not everyone presenting to the blood bank is acceptable as a donor. We investigated the reasons for deferral at a local blood collection centre. Knowing these reasons can help reduce unfruitful trips to the blood bank. It can also assist in guiding different methods of recruitment of prospective donors [7] and thus improve blood supplies. It could also be useful in preventing loss of known donors, especially new donors, and improving the retrieval of those that are temporarily deferred.

\section{Materials and Methods}

Approval was obtained from the ethics committee of the Faculty of Medical Sciences. We collected data on people who presented to the blood collection centre for donation between April 2011 and May 2012. At this centre only whole blood is collected for components preparation. We analyzed the results of those who were deferred during the screening process. The screening process, involved a questionnaire (administered by nurses), a mini medical examination (BP, Pulse, temperature, weight check) then screening for adequacy of haemoglobin. The Pan American Health Organization, (PAHO), 2009 guidelines were used [9]. Male donors may donate again after 3 months and female donors after 4 months. At the start of the study this blood bank was using the copper sulphate $\left(\mathrm{CuSO}_{4}\right)$ method but later converted to the HemoCue method for assessing the adequacy of haemoglobin among donors. The haemoglobin cut off levels were 12.5 $\mathrm{g} / \mathrm{dL}$ for prospective female and $13.5 \mathrm{~g} / \mathrm{dl}$ for male donors as per PAHO guidelines. Standard methods of preparation of $\mathrm{CuSO}_{4}$ were used. The HemoCue $\mathrm{Hb} 201^{+}$was used. The screening and blood collection process was done by nurses. This study analyses the prospective donors deferred based on the initial screening process only. Analysis of the microbial testing is beyond the scope of this study.

\section{Results}

488 people were deferred. 309 (63.3\%) were male and 179 (36.7\%) were female.

In terms of types of donors, $11.6 \%$ were voluntary and $88.4 \%$ were replacement donors.
In terms of ethnicity, $31.6 \%$ were of West African origin, $54.5 \%$ East Indian origin and $13.9 \%$ people of mixed heritage (ethnicity is as reported by the prospective donors themselves).

In terms of haemoglobin assessment method, 293 (60.04\%) had their haemoglobin assessed by the $\mathrm{CuSO}_{4}$ method and 195 (39.96\%) by the HemoCue method (Figures 1-4).

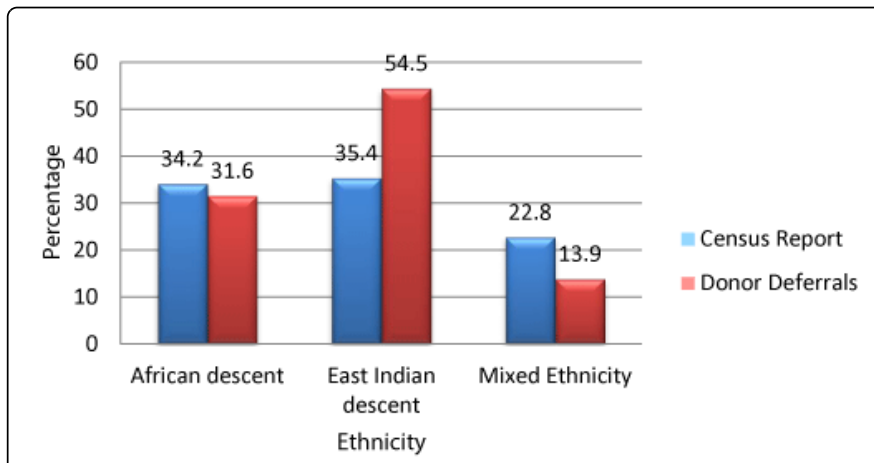

Figure 1: The ethnic distribution of prospective blood deferrals compared to the nation's population.

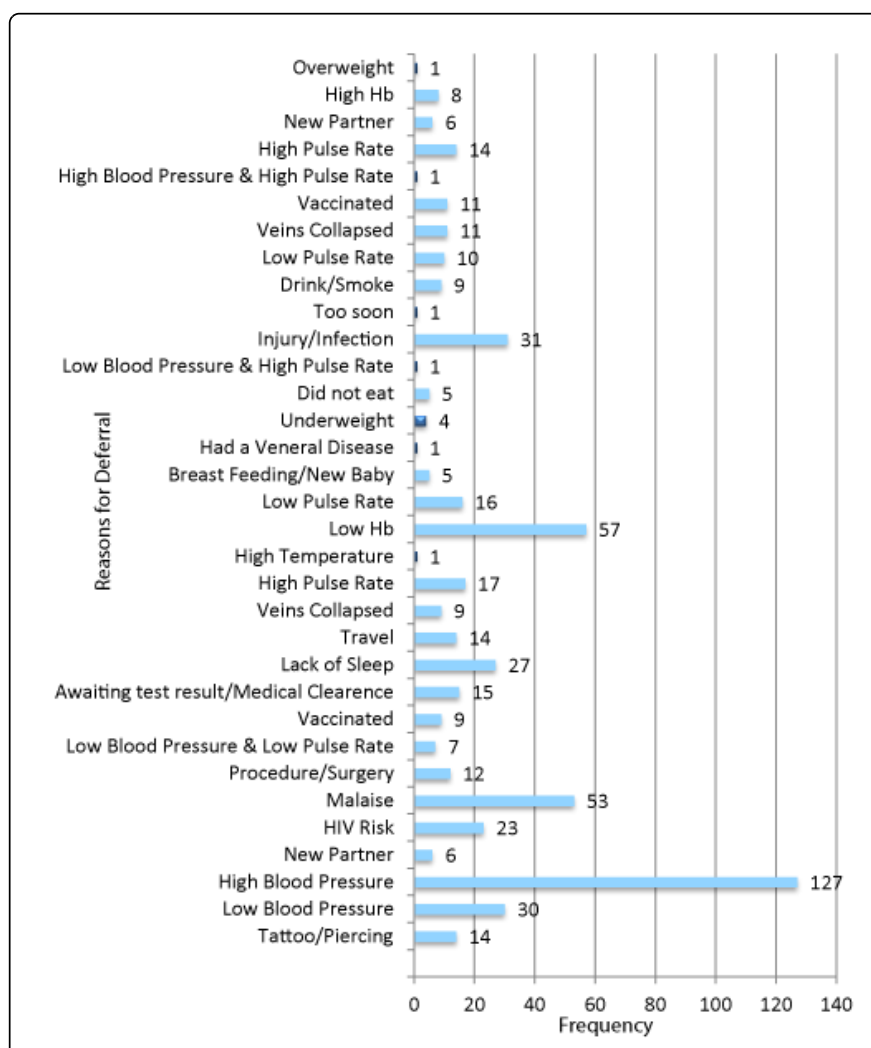

Figure 2: The reasons for deferral at the Eric Williams Medical Sciences Complex (EWMSC) Blood Collection Centre (Total study population: $\mathrm{N}=488$ ). 
Citation: Vuma S, Mayers H, Legall G, Vaillant AAJ (2015) Analysis of Reasons for Prospective Blood Donor Deferrals at Eric Williams Medical Sciences Complex Blood Collection Centre, in Trinidad and Tobago. J Blood Disorders Transf 6: 263. doi:10.4172/2155-9864.1000263

Page 3 of 5

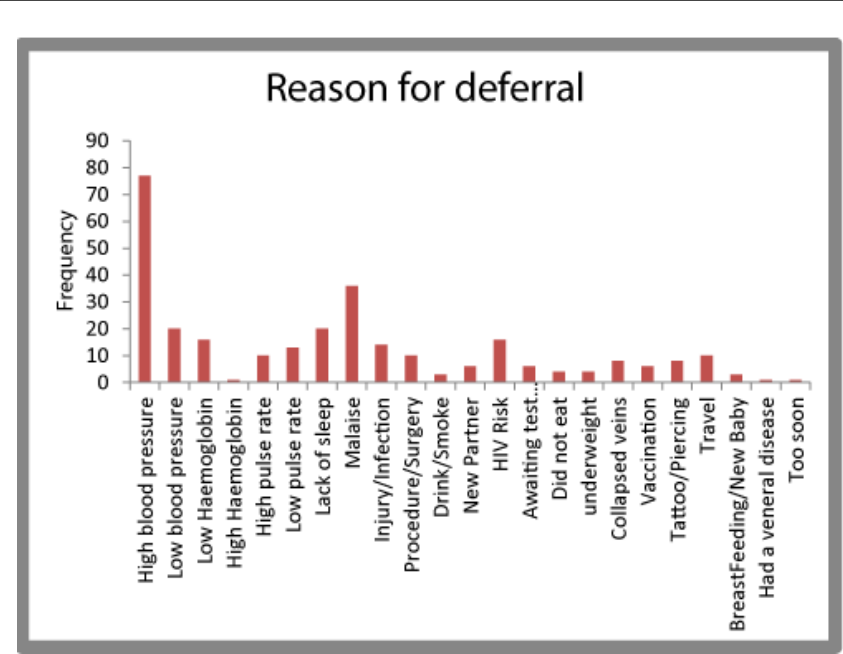

Figure 3: Analysis of 293 subjects ( $\mathrm{Hb}$ assessed using $\mathrm{CuSO}_{4}$ method).

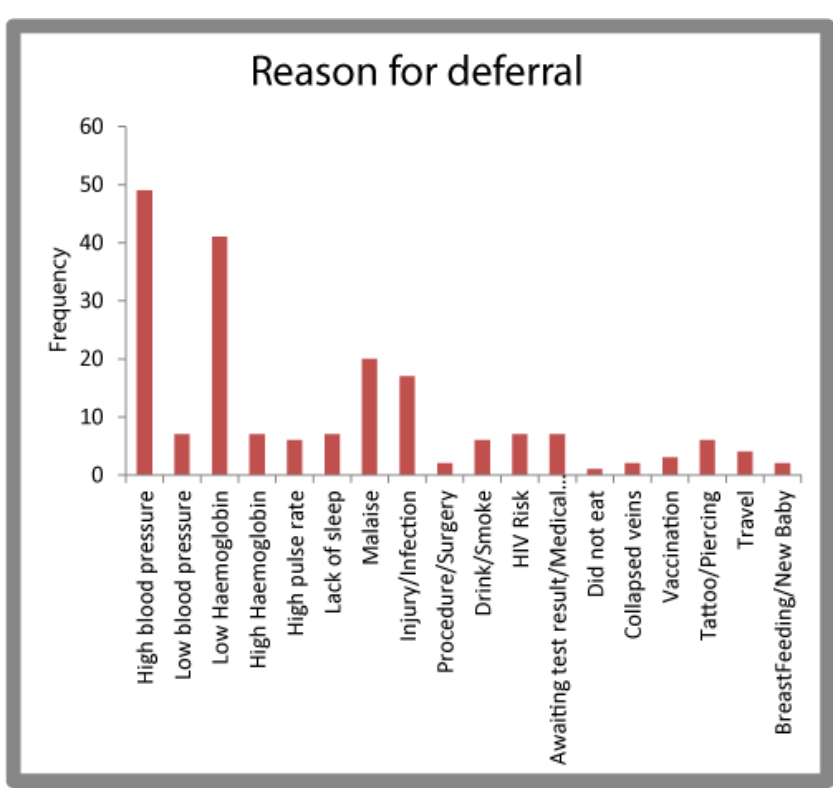

Figure 4: Analysis of 195 subjects ( $\mathrm{Hb}$ assessed using the HemoCue201* method).

The highest reason for deferral was high blood pressure and it was 126 (25.8\%). Some of the deferred subjects had extremely high blood pressures. A lot of them were subjects who were not known to be hypertensive prior. Most of the hypertensive subjects were of East Indian origin (Figure 5). Other reasons for deferral included lack of sleep 27 (5.5\%), not eating prior to coming to the blood bank 5 $(1.02 \%)$, drank alcohol/smoked prior, 9 (1.84\%), tattoo/piercing, 14 $(2.87 \%)$ and even breast feeding, inter-current illnesses and too soon since a previous donation. 57 of the $488(11.7 \%)$ were deferred on the basis of a low haemoglobin, 16 of the 57 (28.1\%) were screened using the $\mathrm{CuSO} 4$ method and 41 (71.9\%) using the HemoCue method. Of the $57,33(57.9 \%)$ were female and $24(42.1 \%)$ were male. The subjects of West African and East Indian origin who were deferred based on low haemoglobin were almost similar in numbers (Figure 5).

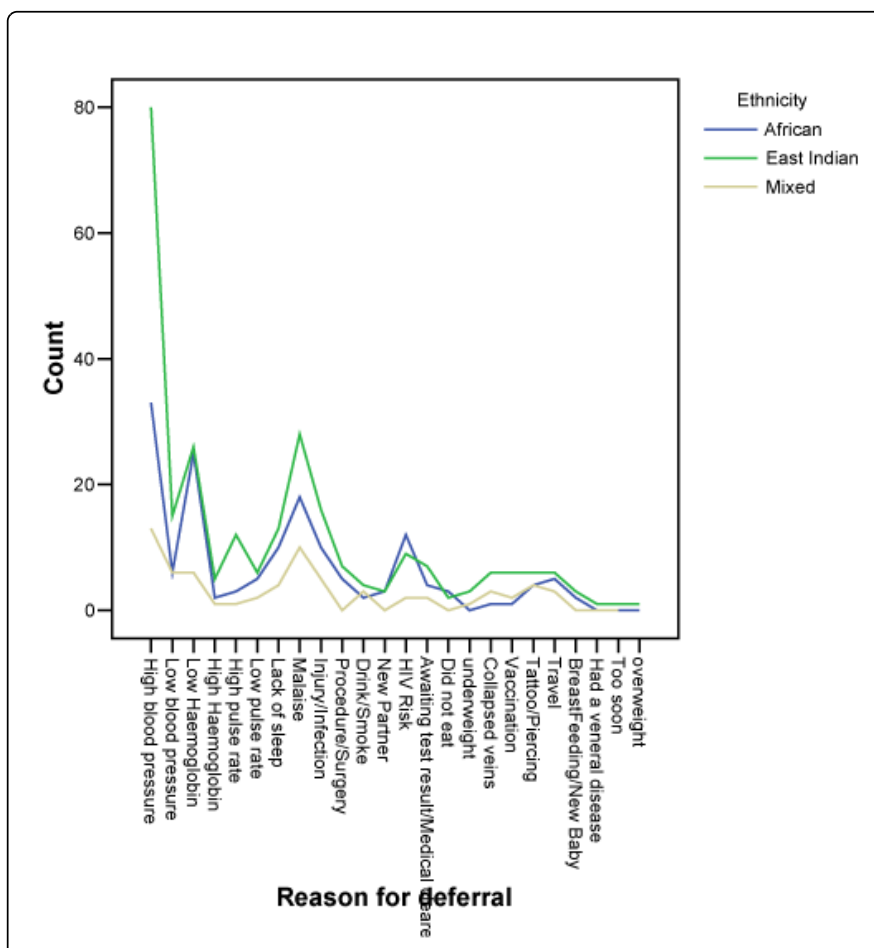

Figure 5: Analysis of deferrals by ethnic groups.

\section{Discussion}

The donor screening procedures are done to not only ensure that the donated blood is safe for the recipient but also that the donation process is safe for the donor. This study shows similar results to the Indian (Jashnani et al. [5] and Shar et al. [2]), (hypertension among people of East Indian descent), and the West African (low haemoglobin) [6,7], studies. Like in the Norwegian study, (Reikvam et al. [1], intercurrent illnesses were seen too but at a smaller percentage in comparison. Some deferrals in this study are not for reasons that would potentially endanger the recipient and can actually be avoided. This is similar to what was reported by Custer et al. [4]. This emphasizes the importance of educating potential blood donor populations before visiting the blood bank, especially in a country which relies mostly on replacement donations. They are also only temporary deferrals.

The temporarily deferred donors need to be encouraged to return. In the Indian study [2], $31.2 \%$ of the temporarily deferred did actually return, and of these $86.54 \%$ were able to donate on their repeat visit. Deferred repeat donors were more likely to return than deferred first time donors. Deferrals of shorter duration are more likely to return than longer those who are longer term. [4]. The majority of the temporarily deferred in our setting are in fact shorter duration deferrals.

In this study a lot of the deferred donors are due to high blood pressure most of them being of East Indian origin. However most of the study population is also East Indian. On World Health Day, 2013 [10] it was reported that according to the Chronic Risk Factor Survey 
by the Ministry of Health, there is a high prevalence of hypertension in Trinidad and Tobago with about $26 \%$ of the population living with hypertension. Derek Chadee et al. [11], also reported a high prevalence of self-reported hypertension in Trinidad (30.2\%) with people of East Indian origin (49.6\%) having the highest over people of African origin $(35.5 \%)$ and people of mixed heritage (14.8\%) in keeping with this study's findings. In comparison, hypertension accounted only for $3.1 \%$ of the reasons for deferral in the West African study done in Nigeria, which also is predominantly replacement donors [7]. Some of the high blood pressure readings in our setting may also be due to anxiety of going to the blood bank for the first time or due to the stress of dealing with a sick relative or friend for whom they are donating. In a study in 2007, about attitudes of blood donors in Trinidad and Tobago, Sampath et al. [12] showed that $87 \%$ were replacement donors and of these $81.3 \%$ had indeed never donated before.

High percentage of deferrals due to low haemoglobin among female donors are in keeping with the donor population being of child bearing age and hence frequent blood loss during menstruation as seen in other studies [6,7]. In our setting, it should also be known that thalassaemia is prevalent among people of East Indian origin, and Sickle cell diseases are common in people of West African origin. There was no difference between the deferrals due to low haemoglobin in the people of East Indian descent compared to those of West African descent. In the West African settings, [6,7] nutrition and malaria were also thought to contribute to the low haemoglobin. In Ivory Coast [6] blood donation itself was noted as a possible cause for low haemoglobin. Their lower cut off for acceptable haemoglobin is even lower, ie haemoglobin of $11 \mathrm{~g} / \mathrm{dL}$ as compared to the PAHO guidelines [9] used in our setting of $12.5 \mathrm{~g} / \mathrm{dL}$ for female donors and $13.5 \mathrm{~g} / \mathrm{dL}$ for male donors. The inter-donation period in that setting is also shorter: three months for the female donors and two and a half months for males. The PAHO guidelines used in our setting is four months for females and three months for males. $4.5 \%$ deferrals had returned too soon even then in the Ivorian setting. In our setting the percentage was lower comparatively.

Potential donors in Trinidad and Tobago should be educated about the blood donation process itself prior to coming to the blood bank so they know what to expect. This may reduce some of the anxiety especially among the first time donors. Reasons like "lack of sleep," "did not eat," and "drinking alcohol/smoking" before reporting to blood bank, or presenting too soon, or too early for a repeat donation, are easily preventable with population education and awareness. Furthermore, such deferrals are in fact a waste of time and unnecessary effort for both prospective donors and blood bank workers [5]. This is especially true where staff shortages are experienced as is the case in Trinidad and Tobago. Hopefully a donor's enthusiasm or willingness to donate is not reduced by this kind of reason for deferral. In a setting with staff shortages, the resulting inconveniences of long waiting periods at the blood bank may further confound matters. The Indian study [5] showed however that most of the temporarily deferred donors were not demotivated and did indeed agree to return to the blood bank.

There is such a shortage of blood in our setting that even women who recently gave birth, or are ill themselves try to donate blood for their family members and sometimes "too soon" before they are eligible to donate again. The proportion of voluntary donations has been decreasing over the years from $17 \%$ in 2002 to $13 \%$ in 2005 [9]. Further education is needed to encourage more voluntary donations. In the Indian study Shar et al. [2], they reported that in the past the majority of donors had been replacement, but at the time of the study, due to efforts to increase the voluntary donor pool, voluntary donors had increased and accounted for $55 \%$ of donors. In the study by Sampath et al. [12] in Trinidad and Tobago, the majority of the new donors cited lack of information as the reason for not donating prior. This is encouraging as it suggests that the voluntary donor pool could potentially be increased with the right educational campaigns.

\section{Limitations}

1. The sample studied is small in number and hence further meaningful statistical analysis was not performed. It does however reflect the bias that the donor population is replacement not voluntary.

2. Further analysis of the donors deferred due to low haemoglobin was not done. The study shows that there are more deferrals when haemoglobin adequacy is assessed using the HemoCue method. Studies have shown higher deferrals with haemocue compared to copper sulphate [13-16]. Further analysis of deferrals due to low haemoglobin, as well as evaluation and comparison of the accuracy of the $\mathrm{CuSO}_{4}$ with the HemoCue screening methods in Trinidad and Tobago will be performed in a follow up study.

3. The comparison of reasons for deferral among repeat donors versus first time donors was not studied. Most donors in this setting are replacement donors, most of who are in fact first time donors [12]. Numbers are small.

\section{Conclusions}

There are high numbers of deferrals due to hypertension, low haemoglobin and reasons that would not pose a threat to blood recipients. These temporary deferrals need to be encouraged to return when the reason for deferral has been corrected. Furthermore there is a need to encourage more voluntary donors in this setting which has predominantly replacement donors.

\section{Acknowledgements}

Blood bank staff, prospective blood donors at The Eric Williams Medical Sciences Complex Blood Collection Centre, and Dr Altheia Jones-Lecointe.

\section{References}

1. Reikvam H, Svendheim K, Røsvik AS, Hervig T (2012) Questionnairerelated deferrals in regular blood donors in norway. J Blood Transfus 2012: 813231 .

2. Shah R, Tulsiani S, Harimoorthy V, Mathur A, Choudhury N (2013) Analysis of efforts to maintain safe donor in main donor pool after completion of temporary deferral period. Asian J Transfus Sci 7: 63-67.

3. Misje AH, Bosnes V, Heier HE (2008) Recruiting and retaining young people as voluntary blood donors. Vox Sang 94: 119-124.

4. Custer B, Schlumpf KS, Wright D, Simon TL, Wilkinson S, et al. (2011) Donor return after temporary deferral. Transfusion 51: 1188-1196.

5. Jashnani KD, Patil LN (2011) Blood donor deferrals: Can this be reduced? Asian J Transfus Sci 5: 60.

6. Kouao MD, Dembelé B, N'Goran LK, Konaté S, Bloch E, et al. (2012) Reasons for blood donation deferral in sub-Saharan Africa: experience in Ivory Coast. Transfusion 52: 1602-1606.

7. Ekwere TA, Ino-Ekanem M, Motilewa OO, Ibanga IA (2014) Pattern of blood donor deferral in a tertiary hospital, South-south, Nigeria: A three- 
Citation: Vuma S, Mayers H, Legall G, Vaillant AAJ (2015) Analysis of Reasons for Prospective Blood Donor Deferrals at Eric Williams Medical Sciences Complex Blood Collection Centre, in Trinidad and Tobago. J Blood Disorders Transf 6: 263. doi:10.4172/2155-9864.1000263

Page 5 of 5

year study review. International Journal of Blood transfusion and Immunohematology 4: 7-13.

8. https://guardian.co.tt/sites/default/files/story/

2011_DemographicReport.pdf.

9. Pan American Health Organization (PAHO) (2009) Eligibility for Blood Donation; Recommendation for education and selection of prospective Donors; Blackwell Publishing Ltd.. Washington, D.C, USA.

10. http://www.health.gov.tt/news/newsitem.aspx?id=417.

11. Chadee D, Seemungul T, Pinto Pereira, LM, Chadee M, Maharaj R, et al.. (2013) Prevalence of self-reported diabetes, hypertension and heart disease in individuals seeking State funding in Trinidad and Tobago, West Indies. Journal of Epidemiology and Global Health 3: 95-103.

12. Sampath S, Ramsaran V, Parasram S, Mohammed S, Latchman S, et al. (2007) Attitudes towards blood donation in Trinidad and Tobago. Transfus Med 17: 83-87.
13. Bhaskaram P, Balakrishna N, Radhakrishna KV, Krishnaswamy K (2003) Validation of hemoglobin estimation using Hemocue. Indian J Pediatr 70: $25-28$.

14. Lewis SM, Emmanuel J (2001) Validity of the haemoglobin colour scale in blood donor screening. Vox Sang 80: 28-33.

15. Sawant RB, Bharucha ZS, Rajadhyaksha SB (2007) Evaluation of hemoglobin of blood donors deferred by the copper sulphate method for hemoglobin estimation. Transfus Apher Sci 36: 143-148.

16. Tondon R, Verma A, Pandey P, Chaudhary R (2009) Quality evaluation of four hemoglobin screening methods in a blood donor setting along with their comparative cost analysis in an Indian scenario. Asian Journal of Transfusion Science 3: 66-69. 